\title{
DESEMPENHO PRODUTIVO E QUALIDADE DE OVOS DE POEDEIRAS LEVES SUBMETIDAS A DIFERENTES NÍVEIS DE DEBICAGEM
}

[Performance and eggs quality of light-weight laying hens submitted to different methods of the beak trimming]

\author{
Silvana Cavalcante Bastos-Leite ${ }^{1 *}$, Joanatha Vidal Gomes ${ }^{2}$, Marcio Gleice Mateus Alves ${ }^{2}$, Claudia de \\ Castro Goulart ${ }^{1}$, Josefa Deis Brito Silva ${ }^{1}$, Fabrizia Melo de Medeiros ${ }^{2}$ \\ 1 Docente do Curso de Zootecnia- CCAB- Universidade Estadual Vale do Acaraú -UVA, Sobral -CE. \\ 2 Discente do Curso de Zootecnia-UVA.
}

\begin{abstract}
RESUMO - Objetivou-se avaliar a influência dos diferentes níveis de debicagem, sobre o desempenho e qualidade dos ovos de poedeiras comerciais leves. Foram utilizadas 216 aves em um delineamento inteiramente casualizado, distribuídas em quatro tratamentos, com seis repetições. Os tratamentos utilizados foram: aves não debicadas, aves debicadas a $7 \mathrm{~mm}$, aves debicadas a $6 \mathrm{~mm}$ e aves debicadas a $5 \mathrm{~mm}$, sendo essa distância tomada da narina ao bico. As variáveis avaliadas foram: mortalidade, consumo de ração (g), produção de ovos (\%), peso dos ovos $(\mathrm{g})$, mortalidade $(\%)$, massa de ovos $(\mathrm{g})$, conversão por massa de ovos $(\mathrm{kg} / \mathrm{kg})$, con versão por dúzia de ovos (kg/dúzia), percentual de albúmen $(\%)$, de gema $(\%)$, de casca $(\%)$, ovos quebrados $(\%)$ e trincados $(\%)$. O consumo e a mortalidade foram significativamente maiores nas aves não debicadas. A conversão por massa e por dúzia de ovos foram piores nas aves não debicadas $(\mathrm{P}<0,05)$. As variáveis de qualidade de ovos não foram influenciadas pelos tratamentos. As debicagens a 5,6 ou $7 \mathrm{~mm}$ de distância da narina ao bico podem ser utilizadas em poedeiras leves sem causar prejuízos sobre o desempenho produtivo ou a qualidade dos ovos.
\end{abstract}

Palavras-Chave: aves de postura; bico; canibalismo; manejo.

\begin{abstract}
The aim of experiment was to evaluate the effect of different methods of the beak trimming on performance and eggs quality of light-weight laying hens. 216 birds were distributed in a completely randomized design with four treatments and six replicates. The treatments evaluated were: hens no beak trimmed, hens beak trimmed to $7 \mathrm{~mm}$, hens beak trimmed to $6 \mathrm{~mm}$ and hens beak trimmed to $5 \mathrm{~mm}$ in relation from nostrils to beak. The variables evaluated were feed intake $(\mathrm{g})$, egg production $(\%)$, egg weight $(\mathrm{g})$, mortality (\%), egg mass $(\mathrm{g})$, conversion per egg mass $(\mathrm{kg} / \mathrm{kg})$, conversion per dozen eggs $(\mathrm{kg} / \mathrm{dz})$, albumen $(\%)$, yolk $(\%)$, eggshell $(\%)$, broken eggs (\%) and cracked eggs (\%). There was effect of treatments on variables evaluated. The hens no beak trimmed shown higher feed intake and mortality then other treatments. The conversion per mass and dozen eggs $(\mathrm{kg} / \mathrm{dz})$ was few to hens no beak trimmed $(\mathrm{P}<0.05)$. There was no effect of treatments on eggs quality variables. The beak trimming to 5,6 or $7 \mathrm{~mm}$ in relation from nostrils to beak can used to laying hens.
\end{abstract}

Keywords: cannibalism; beak; laying hen; management.

\footnotetext{
* Autor para correspondência. E-mail: silvanabastos2000@ yahoo.com.br Recebido: 30 de dezembro de 2015.

Aceito para publicação: 04 de maio de 2016.
} 


\section{INTRODUÇÃO}

O bem-estar é um dos assuntos mais debatidos atualmente na produção animal. O final do século XX e início do século XXI foram marcados pelo surgimento de movimentos voltados ao bem-estar animal, destinados a impulsionar ou exigir a adoção de normas e propostas de investimentos nas áreas pertinentes à qualidade de vida dos animais, segurança alimentar e práticas de manejo adotadas na criação de animais (Fraser, 2006; Rocha et al., 2008).

O segmento avícola alcançou um grande desenvolvimento nos últimos anos, e busca novas maneiras de criação com o objetivo de conseguir maior produtividade em menos tempo, com a ajuda do melhoramento genético, nutrição, manejo e sanidade, sendo estes considerados fundamentais ao crescimento da avicultura, com consequente fornecimento de alimentos para a população (Albuquerque, 2004).

A prática da debicagem é comum na criação de galinhas poedeiras, tendo por finalidade a prevenção do canibalismo, mortalidade, lesões associadas ao arranque de penas entre as aves, bem como a queda do desempenho produtivo, além de proporcionar menor desperdício da ração, favorecendo a conversão alimentar (Ávila et al., 2009; Carruthers et al., 2012).

Na produção industrial de poedeiras, normalmente são realizadas duas debicagens, a primeira entre sete e dez dias de vida e a segunda, entre doze a quatorze semanas de idade (Hy-Line do Brasil, 2015). A primeira costuma ser discreta também chamada de leve, onde remove-se a terça parte superior do bico e apenas a extremidade distal inferior deste (Santos, 2014). Assim, se o procedimento for realizado corretamente, não existem complicações ao desempenho animal.

Na segunda debicagem, por falta de padronização dos tamanhos nos cortes dos bicos, muitas vezes são realizadas debicagens severas, onde são realizados cortes empiricamente, sem a devida observação das danosas consequências, que um procedimento destes, pode trazer à vida produtiva das poedeiras. Araújo et al. (2005), relataram que as poedeiras debicadas severamente apresentaram um baixo consumo de ração e menor taxa de postura quando comparadas às aves com debicagem leve.

Um aspecto importante em poedeiras alojadas em gaiolas convencionais é a alta incidência da bicagem, principalmente em lotes submetidos a situações de estresse, como por exemplo, em ambientes com elevadas temperaturas. Segundo Keeling (1995) a ocorrência deste comportamento, é influenciada por fatores hormonais. Nestes casos, a perda de penas decorrente da agressão de uma ave dominante pode causar tantos problemas econômicos ao produtor como afetar o bem-estar das aves, prejudicando o seu desempenho produtivo.

Um dos maiores desafios para os produtores de aves de postura é alcançar um nível de debicagem adequada (Hunton, 1998). Por isto, a debicagem é considerada um procedimento de precisão onde, as falhas devem ser minimizadas para assegurar a produtividade futura da ave. Este processo é realizado com o auxílio de um aparelho próprio e consiste no corte parcial do bico da ave.

$\mathrm{Na}$ produção de poedeiras comerciais não existe uma padronização dos tamanhos de corte dos bicos das aves, encontrando-se uma gama de comprimentos, formas, além de variáveis temperaturas dos aparelhos debicadores, nos processos de debicagem. Esta falta de normalização tem causado injúrias às aves, dificultando a cicatrização dos bicos, levando a desuniformidade dos lotes, causando prejuízos muitas vezes irreparáveis aos criadores. Diante do exposto, objetivou-se avaliar a influência dos diferentes níveis de debicagem, sobre o desempenho e qualidade dos ovos de poedeiras comerciais leves.

\section{MATERIAL E MÉTODOS}

A pesquisa foi conduzida na Fazenda Experimental da Universidade Estadual Vale do Acaraú - UVA. O desempenho e a qualidade de ovos de poedeiras comerciais leves da linhagem Hy-Line White, foram avaliados no período experimental de 140 dias, dividido em cinco ciclos de 28 dias. Utilizaram-se 216 aves da $25^{\mathrm{a}}$ a $41^{\mathrm{a}}$ semanas de idade, pesando $1,452 \pm 0,029 \mathrm{~kg}$.

Adotou-se um delineamento inteiramente casualizado, com quatro tratamentos e seis repetições de nove aves. Os tratamentos consistiram em: aves não debicadas, aves debicadas a 7 (mm), aves debicadas a $6 \mathrm{~mm}$ e aves debicadas a $5 \mathrm{~mm}$, sendo estas medidas tomadas com o auxílio de um paquímetro, correspondendo à distância da narina ao bico após o corte e cauterização deste.

As aves foram alojadas em gaiolas convencionais. As rações foram formuladas à base de milho e farelo de soja, isonutrientes (Tabela 1), e a composição dos ingredientes utilizados seguiu a recomendação de Rostagno et al. (2011). 
Tabela 1. Composição percentual e nutricional calculada da ração experimental.

\begin{tabular}{lc}
\hline INGREDIENTES & QUANTIDADE (\%) \\
\hline Milho grão & 63,466 \\
Farelo de soja $(45 \%)$ & 23,984 \\
Óleo de soja & 0,730 \\
Fosfato bicálcico & 1,505 \\
Calcário Calcítico & 9,247 \\
Sal comum & 0,478 \\
Metionina & COMPOSIÇÃO NUTRICIONAL CALCULADA \\
PX POSTURA 0,4\% * & 0,190 \\
\hline & 0,400 \\
\hline Energia Metab. (Cal/kg) & 2.800 \\
Proteína Bruta (\%) & 16,5 \\
Cálcio (\%) & 4,02 \\
Fosforo disponível (\%) & 0,375 \\
Sódio (\%) & 0,225 \\
Metionina + Cistina digestível (\%) & 0,662 \\
Metionina digestível (\%) & 0,428 \\
Lisina digestível (\%) & 0,736 \\
\hline Compaça básica por & \\
\hline
\end{tabular}

*Composição básica por kg do produto: Vitamina A: 5.000.000UI; Vitamina D3: 1.100.000UI, Vitamina E: 4.000UI, Vitamina K3: $1.000 \mathrm{mg}$; Vitamina B1: 500,0857 mg; Vitamina B2: $1500 \mathrm{mg}$; Vitamina B6: 500,20 mg; Vitamina B12: $3000 \mathrm{mcg}$; Cloreto de Colina: 43.001,0143 mg, Biotina: $10 \mathrm{mg}$, Niacina: $10000 \mathrm{mg}$; Acido Fólico: 100,4286 mg; Acido pantotênico: 4.600,2857 mg; Sulfato de Cobalto: $50 \mathrm{mg}$; Sulfato de Cobre: 3000mg; Sulfato de Ferro: $25.000 \mathrm{mg}$; Sulfato de Zinco: 25.000mg; Iodato de Cálcio: 500,4mg; Sulfato de Manganês: 25.000,1714mg; Selenito de Sódio: 100,2571mg; Metionina: 495.000mg, BIOTOP: 75000mg; Aditivo Antioxidante: 2000mg; Veículo q. s. p.

As aves passaram por duas debicagens a primeira leve aos 9 dias de vida e a segunda, onde foram feitas medições que comporiam os tratamentos, as 13 semanas de idade. Após esse momento as aves foram identificadas e separadas nas gaiolas, onde ocorreu a completa cicatrização do bico, até a montagem do experimento que aconteceu as 25 semanas de idade.

Para realização dos cortes dos bicos utilizou-se o debicador da marca Lyon 50/60 hertz, 70-210 watts. $\mathrm{Na}$ primeira debicagem o aparelho foi regulado para operar com $550^{\circ} \mathrm{C}$ e na segunda o mesmo operou com a temperatura de $750^{\circ} \mathrm{C}$, para realização dos cortes.

Nas três semanas seguintes à segunda debicagem trabalhou-se com o nível de ração mais alto nos comedouros, a fim de evitar que as aves machucassem os bicos, no período necessário à completa cicatrização destes. Durante a cicatrização dos bicos não foi utilizado nenhum tipo de medicamento, para apressar o processo, apenas cuidados foram tomados, quanto ao arraçoamento, com o mencionado anteriormente.

Excetuando, o período mencionado, as aves foram alimentadas antes e durante o experimento com a quantidade de ração diária, conforme o consumo sugerido pelo manual da linhagem, em relação à idade das mesmas. A água era fornecida ad libitum diariamente para as aves.

Entre dez e vinte semanas de idade as frangas receberam apenas iluminação natural. No entanto, durante a fase de postura, o programa de luz utilizado, incluía 16 horas ao todo, sendo quatro destas, iluminação artificial.

O desempenho das aves foi avaliado ao final de cada período de 28 dias, através das seguintes variáveis: consumo de ração $(\mathrm{g})$, produção de ovos $(\%)$, peso dos ovos $(\mathrm{g})$, mortalidade $(\%)$, massa de ovos (g/ave/dia), conversão por massa de ovos $(\mathrm{kg} / \mathrm{kg})$ e conversão por dúzia de ovos $(\mathrm{kg} / \mathrm{dz})$. Diariamente, as aves eram observadas para verificação de possíveis mortes, estas eram retiradas das gaiolas, examinadas e este dado registrado, para o posterior cálculo da mortalidade (\%) ao final de cada ciclo.

As análises das variáveis de qualidade dos ovos foram realizadas ao final de cada período de 28 dias, utilizando-se dois ovos de cada parcela, por três dias consecutivos, avaliando-se os percentuais de albúmen, gema, casca. Diariamente, juntamente 
com a apanha dos ovos viáveis eram também coletados e registrados os ovos trincados e quebrados, para posterior análise na finalização do ciclo.

Os dados foram submetidos à análise de variância pelo Programa Estatístico SAS (2000) e as médias comparadas pelo teste de Tukey a $5 \%$ de probabilidade. Os valores de percentagem de ovos quebrados e trincados foram submetidos à transformação de dados (transformação raiz quadrada) antes das análises estatísticas.

\section{RESULTADOS E DISCUSSÃO}

Houve diferença $(\mathrm{P}<0,05)$ dos métodos de debicagem sobre as variáveis de consumo de ração e mortalidade (Tabela 2). O maior consumo de ração foi observado nas aves não debicadas e o menor consumo nas aves debicadas a $6 \mathrm{~mm}$. O processo de debicagem, além de evitar que as aves selecionem os alimentos (Laganá et al., 2011), também inibe o desperdício de ração pelas mesmas (Araújo et al., 2005).

Na literatura existem vários relatos semelhantes em relação ao consumo de ração das aves não debicadas, como os mencionados por Leandro et al. (2005) e Laganá et al. (2011), que trabalhando com três tipos de debicagem em codornas, também registraram maior consumo nas aves sem debicagem.

Tabela 2. Médias das características de desempenho produtivo de poedeiras comerciais submetidas a diferentes métodos de debicagem.

\begin{tabular}{lccccccc}
\hline Tratamento & $\begin{array}{c}\text { Mortalidade } \\
(\%)\end{array}$ & $\begin{array}{c}\text { CR } \\
(\mathrm{g} / \mathrm{ave} / \mathrm{dia})\end{array}$ & $\begin{array}{c}\text { PRO } \\
(\%)\end{array}$ & $\begin{array}{c}\text { PO } \\
(\mathrm{g})\end{array}$ & $\begin{array}{c}\mathrm{MO} \\
(\mathrm{g} / \mathrm{ave} / \mathrm{dia})\end{array}$ & $\begin{array}{c}\text { CAMA } \\
(\mathrm{kg} / \mathrm{kg})\end{array}$ & $\begin{array}{c}\text { CADZ } \\
(\mathrm{kg} / \mathrm{dz})\end{array}$ \\
\hline $\begin{array}{l}\text { Sem } \\
\text { Debicagem }\end{array}$ & $1,50 \mathrm{a}$ & $93,6 \mathrm{a}$ & 90,9 & 58,6 & 53,2 & $1,758 \mathrm{a}$ & $1,235 \mathrm{a}$ \\
$\begin{array}{l}\text { Debicagem } \\
(7 \mathrm{~mm})\end{array}$ & $0,17 \mathrm{~b}$ & $91,2 \mathrm{ab}$ & 92,6 & 57,7 & 53,4 & $1,706 \mathrm{ab}$ & $1,181 \mathrm{~b}$ \\
$\begin{array}{l}\text { Debicagem } \\
(6 \mathrm{~mm})\end{array}$ & $0,33 \mathrm{~b}$ & $89,0 \mathrm{~b}$ & 90,9 & 57,7 & 52,5 & $1,696 \mathrm{~b}$ & $1,175 \mathrm{~b}$ \\
$\begin{array}{l}\text { Debicagem } \\
(5 \mathrm{~mm})\end{array}$ & $0,00 \mathrm{~b}$ & $89,4 \mathrm{ab}$ & 90,5 & 58,3 & 52,8 & $1,693 \mathrm{~b}$ & $1,184 \mathrm{~b}$ \\
\hline Média & 0,50 & 90,8 & 91,2 & 58,1 & 52,9 & 1,713 & 1,194 \\
\hline CV $(\%)$ & 20,8 & 3,04 & 1,66 & 1,71 & 2,58 & 2,05 & 2,19 \\
\hline
\end{tabular}

Letras na mesma coluna diferentes diferem-se estatisticamente pelo Teste de Tukey a 5\%. CR - Consumo de ração; PRO - Produção de ovos; PO - Peso do ovo; MO - Massa de ovos; CAMA - Conversão por massa de ovos; CADZ - Conversão por dúzia de ovos.

A elevada taxa de mortalidade presente nos tratamentos sem debicagem foi causada por canibalismo, tendo sido constatada pelos achados de necropsia. O comportamento da referida variável pode ser justificado pelo fato de que aves criadas em gaiolas são propensas a desenvolverem agressividade umas com as outras, sendo que a presença do bico intacto pode intensificar esse comportamento, levando-as ao canibalismo, com consequente aumento da mortalidade. A alta densidade de alojamento e as condições climáticas são fatores que podem acentuar a agressividade das aves, predispondo-as a reações como bicagem e canibalismo, assim a debicagem pode ser benéfica, pois proporciona menor mortalidade (Leandro et al., 2005).

Resultados semelhantes foram relatados por Guesdon et al. (2006), que trabalhando com poedeiras submetidas ou não à debicagem, verificaram uma taxa superior de mortalidade associada ao canibalismo em aves não debicadas, enfatizando as consequências no desempenho e grandes perdas econômicas, em caso de preservação do bico integro. Mertens et al. (2009) também relataram elevada mortalidade, no grupo de poedeiras não debicadas

As aves não debicadas apresentaram pior conversão alimentar por massa e por dúzia de quando comparadas às aves debicadas (Tabela 2). Para a conversão por massa de ovos, os tratamentos a 5, 6 e $7 \mathrm{~mm}$ da narina não diferiram estatisticamente entre si. Para conversão por dúzia de ovos, os melhores resultados também foram verificados nas aves debicadas a $5 \mathrm{~mm}$ da narina ao bico, sendo este semelhante aos demais tratamentos.

Os melhores resultados para conversão alimentar observados nas aves debicadas, provavelmente, podem ser atribuídos não somente ao menor desperdício de ração (Araújo et al., 2005), mas também à redução da capacidade de selecionar partículas de ração (Laganá, et al., 2011), evitando 
assim, o desbalanceamento da mesma na hora da ingestão, proporcionando os resultados verificados.

Para Leandro et al. (2005) poedeiras não-debicadas resultam em pior conversão alimentar devido ao maior desperdício de ração. Pizzolante et al. (2007), em seu trabalho com codornas japonesas (não debicadas, corte $1 / 3$ e $1 / 2$ do bico), encontraram melhores resultados de conversão alimentar nas aves não debicadas e nas aves com $1 / 3$ do bico cortado. No entanto, Araújo et al. (2005) trabalhando com poedeiras comerciais (não debicadas, debicagem leve e severa), relatam que a conversão alimentar não foi influenciada pelos métodos de debicagem.

Não houve efeito dos métodos de debicagem sobre nenhuma das variáveis de qualidade dos ovos (Tabela 3).

Tabela 3. Qualidade de ovos de poedeiras comerciais leves, submetidas a diferentes métodos de debicagem.

\begin{tabular}{lccccc}
\hline Tratamento & Albúmen $(\%)$ & Gema $(\%)$ & Casca $(\%)$ & Ovos quebrados $(\%)$ & Ovos trincados $(\%)$ \\
\hline Sem Debicagem & 60,3 & 26,1 & 9,6 & 0,44 & 0,18 \\
Debicagem (7 mm) & 60,2 & 25,6 & 9,3 & 0,67 & 0,28 \\
Debicagem (6 mm) & 60,7 & 25,4 & 9,6 & 0,56 & 0,32 \\
Debicagem $(5 \mathrm{~mm})$ & 61 & 25,7 & 9,5 & 0,52 & 0,36 \\
\hline Média & 60,6 & 25,7 & 9,5 & 0,57 & 0,28 \\
\hline CV $(\%)$ & 1,88 & 2,27 & 2,67 & 13,9 & 11,2
\end{tabular}

Médias na mesma coluna seguidas de letras iguais não diferem estatisticamente entre si pelo Teste de Tukey a $5 \%$.

A dieta experimental foi formulada de forma a suprir as exigências nutricionais necessárias, à formação de ovos de qualidade. Como a dieta utilizada foi a mesma em todos os tratamentos, possíveis variações no consumo de ração causadas pelos diferentes tamanhos de bico, poderiam levar a falhas no suprimento de nutrientes, assim influenciando a qualidade dos ovos, fato não observado no presente experimento. Desta forma, não ocorrendo prejuízos à formação do ovo e, portanto, à sua qualidade.

Adicionalmente à boa nutrição, fatores físicos como a qualidade das instalações, podem causar injúrias às cascas dos ovos. As gaiolas onde foi realizada a pesquisa eram novas e apresentavam declividade adequada, onde o contato das aves debicadas ou não, com os ovos era breve. Diante disto, podemos inferir que a qualidade das gaiolas pode ter contribuído para ausência de diferenças nos resultados de ovos quebrados e trincados.

O canibalismo causado pelas aves com o bico integro, entre outros problemas, leva a uma perda econômica significativa, no que se refere ao aumento na incidência de ovos bicados. Para Gonçalves et al. (2010), as aves dominantes ao bicarem as demais aves da gaiola provocam um estresse crônico nestas, prejudicando índices produtivos e, afetando a qualidade dos ovos. No presente experimento, tal comportamento, não foi suficiente, para afetar a qualidade dos ovos, mesmo entre as companheiras de gaiola.

Resultados semelhantes foram relatados por Oda et al. (2000), que trabalhando com aves da linhagem Lohmann e Isa Babcock, também não observaram nenhuma diferença no percentual de ovos quebrados das aves debicadas ou não. Laganá et al. (2011) trabalhando com codornas japonesas submetidas a tratamentos que incluíram 3 tipos de debicagem (não debicadas, 1/3 do bico e cauterização), verificaram que os tipos de debicagem não influenciaram o percentual de albúmen e da gema. Da mesma forma, Pizzolante et al. (2007) observaram que codornas debicadas severamente ( $1 / 2$ bico), reduziram o consumo de ração, sem, entretanto, influenciar a qualidade dos ovos.

\section{CONCLUSÕES}

As debicagens a 5, 6 ou $7 \mathrm{~mm}$ de distância da narina ao bico podem ser utilizadas em poedeiras leves, sem causar prejuízos sobre o desempenho produtivo ou a qualidade dos ovos.

\section{REFERÊNCIAS}

ALBUQUERQUE, R. Tópicos importantes na produção de poedeiras comerciais. Avicultura Industrial, v. 1121, n. 95, p. $53-56,2004$

ARAÚJO, L.F. et al. Desempenho de poedeiras comerciais submetidas ou não a diferentes métodos de debicagem. Revista Ciencia Rural, v. 35, n. 1, p. 169-173, 2005

ÁVILA, V. S.; ROLL, V.F.B.; CATALAN, A.A.S. Debicagem em reprodutoras e poedeiras comerciais. Avicultura Industrial, v. 1175 , n. 2 , p. $16-20,2009$.

CARRUTHERS, C. et al. On-farm survey of beak characteristics in White Leghorns as a result of hot blade trimming or infrared beak treatment. Applied Poultry Research v. 21, n. 3, p. 645$650,2012$. 
FRASER, D. Animal welfare assurance programs in food production: a framework for assessing the options. Animal Welfare, v. 15, n. 2, p. 93-104, 2006.

GONÇALVES, F.M. et al. Administração de antibiótico em poedeiras semipesadas durante o processo de debicagem. Archivos de Zootecnia, v. 59, n. 226, p. 295-298, 2010.

GUESDON V. et al. Effects of beak trimming and cage design on laying hen performance and egg quality. British Poultry Science, v. 47, n. 1, p. 1-12, 2006.

HUNTON, P. The beak trimming controversy. World Poultry, v. 14, n. 2 , p. $42-43,1998$.

HY LINE DO BRASIL. Manual da linhagem: Poedeiras Comerciais HyLine White. 2015. Acessado em 01 de março de 2016. Online. Disponível em: http://www.hyline.com/UserDocs/pages/36 COM POR.pdf

KEELING, L.J. Feather pecking and cannibalism in layers. Poultry International, v. 34, n. 6, p. 46-49, 1995.

LAGANÁ, C. et al. Influência de métodos de debicagem e do tipo de bebedouro no desempenho e na qualidade dos ovos de codornas japonesas. Revista Brasileira de Zootecnia, v. 40, n. 6, p. 1217-1221, 2011.

LEANDRO, N.S.M. et al. Desempenho produtivo de codornas japonesas (Coturnix coturnix japonica) submetidas a diferentes densidades e tipos de debicagem. Acta Scientiarum Animal Sciences, v. 27, n. 1, p. 129-135, 2005.
MERTENS, K. et al. Layers in aviary system: Effects of beak trimming and alternative feed formulation on technical results and egg quality. Journal of Applied Poultry Research. v. 18, n. 1, p. 90-102, 2009.

ODA, P.K. et al. Desempenho comparativo entre duas linhagens de poedeiras comerciais debicadas em diferentes idades na fase de recria. Ciência Rural, v. 30, n. 4, p. 693- 698, 2000.

PIZZOLANTE, C.C. et al. Break trimming methods and their effect on the performance and egg quality of Japanese quails (Coturnix japonica) during lay. Revista Brasileira de Ciência Avícola, v. 9, n. 1, p. 7-21, 2007.

ROCHA, J. S. R.; LARA, L.J.C.; BAIÃO, N.C. Produção e bem-estar animal: Aspectos éticos e técnicos da produção intensiva de aves. Ciência Veterinária dos Trópicos, v. 11, n. 1, p. 49-55, 2008.

ROSTAGNO, H.S. et al. Tabelas brasileiras para aves e suínos: composição de alimentos e exigências nutricionais. 3. ed. Viçosa: UFV. 2011. 252 p.

SANTOS, T.A. Métodos de debicagem em poedeiras comerciais. 2014. 76p. Dissertação (Mestrado em Zootecnia) Universidade Estadual Paulista, Faculdade de Medicina Veterinária e Zootecnia, Botucatu, 2014.

SAS ®.2000.User's Guide: Statistics, Version 10th. SAS InstituteInc.,Cary, NC. 